\title{
PENGARUH METODE LATIHAN FIGURE EIGHT WITH DRIBBLING DAN METODE LATIHAN NECK WAIST AND LEG CIRCLES TERHADAP HASIL DRIBBLE PADA HURRICANE BASKETBALL CLUB DI KECAMATAN GEMOLONG
}

\author{
Seno Widyantoro ${ }^{a}$, Agustanico Dwi Muryadi, M. Pd. ${ }^{b}$, Karlina Dwijayanti, S.Pd., M.Pdc \\ Physical Education, University of Tunas Pembangunan, Surakarta, Indonesia
}

Email: ${ }^{a}$ Senowidyantoro16@gmail.com

I N F O A R T I K E L

Sejarah artikel:

Menerima1Juli2021

Revisi21Juli2021

Diterima 22

Online 30 Juli 2021

\section{Kata kunci:}

Bola Basket

Dribbling Figure Eight, Dribbling

Neck Waist And Leg Circle

Keywords:

Basketball

Dribbling Figure Eight, Dribbling

Neck Waist, And Leg Circle
Style APA

dalammensitasiartikelini:[Heading sitasi]

Seno Widyantoro. (2021) Pengaruh Metode Latihan Figure Eight With Dribbling dan Metode Latihan Neck Waist And Leg Circles Terhadap Hasil Dribble pada Hurricane Basketball Club di Kecamatan Gemolong.

Jurnal Ilmiah Penjas (7.2) (1-12)
ABSTRAK

Penelitian ini bertujuan untuk mengetahui perbedaan Metode Latihan Figure Eight With Dribbling dan Metode Latihan Neck Waist And Leg Circles Terhadap Hasil Dribble pada Hurricane Basketball Club di Kecamatan Gemolong. Penelitian eksperimen kuantitatif pretest post-test design. Penelitian ini dilakukan pada Hurricane Basketball Club. Dilaksanakan dari bulan Juni sampai bulan Desember 2020 diawali pretest, diberikan perlakuan dan diakhiri post-test. Subjek penelitian ini adalah pemain Hurricane Basketball Club kelompok SMA yang berjumlah 30 orang. Teknik pengumpulan data menggunakan tes dribble zig-zag. Analisis data menggunakan uji prasyarat analisis data (uji normalitas dan uji homogenitas) dan uji perbedaan. Hasil penelitian menunjukan bahwa terdapat pengaruh hasil Metode Latihan Figure Eight With Dribbling dan Metode Latihan Neck Waist And Leg Circles Terhadap Hasil Dribble pada Hurricane Basketball Club di Kecamatan Gemolong Tahun 2020, karena nilai t yang diperoleh sebesar 7,006 lebih besar dari t tabel 2,045 dan angka signifikan $0,000<0,05$ sehingga ada perbedaan signifikan nilai hasil kemampuan dribble dan menunjukan adanya pengaruh yang berbeda antara kedua kelompok setelah diberi perlakuan. Berdasarkan hasil perhitungan menunjukkan pada kelompok Figure Eight With Dribbling dengan nilai rata-rata hasil akhir sebesar 37,07 dan untuk kelompok Neck, Waist And Leg Circles dengan nilai rata-rata hasil akhir sebesar 32.20. menunjukan bahwa kelompok Figure Eight With Dribbling lebih baik pengaruhnya terhadap hasil dribble pada Hurricane Basketball $C l u b$ di Kecamatan Gemolong.

\section{ABSTRACT}

This study aims to determine the differences in the Figure Eight With Dribbling Exercise Method and the Neck Waist And Leg Circles Training Method on the Dribble Results at the Hurricane Basketball Club in Gemolong District.. This research is a quantitative experimental research pretest post-test design. This research was conducted at the Hurricane Basketball Club. Conducted from 
Pengaruh Metode Latihan Figure Eight With Dribbling dan Metode Latihan Neck Waist And Leg Circles Terhadap Hasil Dribble pada Hurricane Basketball Club di Kecamatan Gemolong

Seno Widyantoro, Agustanico Dwi Muryadi, Karlina Dwijayanti

June to December 2020 starting with the pretest, given treatment and ending with the post-test. The subjects of this study were 30 high school group Hurricane Basketball Club players. Data collection techniques using the dribble zig-zag test. Data analysis used data analysis prerequisite test (normality test and homogeneity test) and difference test. The results showed that there was an effect of the Figure Eight With Dribbling Exercise Method and the Neck Waist And Leg Circles Training Method on the Dribble Results at the Hurricane Basketball Club in Gemolong District in 2020, because the $t$ value obtained was 7,006 greater than $t$ table 2.045 and the number was significant. $0.000<0.05$ so that there is a significant difference in the value of the dribble ability and shows that there is a different effect between the two groups after being given treatment. Based on the calculation results, the Figure Eight With Dribbling group with an average final score of 37.07 and for the Neck, Waist and Leg Circles group with an average final score of 32.20. shows that the Figure Eight With Dribbling group has a better effect on dribbling results at the Hurricane Basketball Club in Gemolong District.

\section{Pendahuluan}

Olahraga merupakan kegiatan yang tidak terpisahkan dalam setiap kehidupan manusia dan merupakan keinginan yang dimilki oleh setiap individu manusia. Pemerintah berkewajiban untuk memenuhi kebutuhan akan setiap kegiatan olahraga. Hal ini dilakukan untuk mensejahterakan masyarakat selain itu berguna mewujudkan sumber daya manusia yang berkualitas sehat jasmani dan rohani yang tertuang dalam Undang-Undang Nomor 3 tahun 2005 tentang Sistem Keolahragaan Nasional yang menyatakan bahwa keolahragaan nasional bertujuan untuk memelihara dan meningkatkan kesehatan dan kebugaran, prestasi, kualitas manusia, menanamkan nilai moral dan akhlak mulia, sportivitas, disiplin, mempererat dan membina persatuan dan kesatuan bangsa, memperkukuh ketahanan nasional, serta mengangkat harkat, martabat, dan kehormatan bangsa.

Bola basket adalah cabang olahraga dengan menggunakan bola besar yang dimainkan dengan tangan. Bola basket merupakan olahraga yang dimainkan oleh dua regu yang masing-masing terdiri dari 5 orang pemain. Tiap regu berusaha 
memasukan bola ke dalam keranjang lawan dan mencegah regu lawan memasukan bola atau membuat skor. Permainan bola basket lamanya bermain dibatasi oleh waktu. Menurut Perbasi yaitu 4 x 10 menit dengan masa istirahat 2 menit di antara periode pertama dan kedua, periode ketiga dan keempat istirahat 15 menit. Bola basket termasuk cabang olahraga yang komplek gerakannya, terdiri dari gabungan unsur-unsur gerakan yang terkoordinasi dengan rapi, sehingga memerlukan waktu yang cukup lama untuk mempelajari atau menguasai teknik dasar secara baik dan teratur. Penguasaan teknik dasar sangatlah penting dalam suatu pertandingan bola basket, dengan penguasaan teknik yang baik dan benar maka tidak menutup kemungkinan team tersebut akan mudah mencapai kemenangan. Apabila penguasaan teknik dasar sudah dikuasai dengan baik maka akan menunjang keterampilan bermain selanjutnya. Untuk mencapai prestasi yang tinggi, setiap pemain harus menguasai teknik dasar dan taktik bermain, sehingga terbentuk suatu team yang solid. Untuk menjadi pemain yang baik perlu menguasai fundamental (dasar-dasar teknik, dan strategi) dari permainan bola basket ini. Dengan petunjuk serta mengenal lebih mendalam mengenai dasar-dasar permainan dan peraturan permainan yang berlaku di dunia internasional, maka akan lebih baik dan bertambah maju untuk permainan yang kita sajikan. Menurut Drs Sucipto (2010:10) teknik dasar dalam permainan bola basket adalah sebagai berikut: teknik throwing and catching, teknik dribbling, teknik shooting, teknik pivot, dan teknik layup.

Dribble merupakan salah satu ciri khas yang tidak dapat dipisahkan dalam permainan bola basket. Selain itu teknik menggiring bola dalam permainan bola basket sangatlah penting dan vital. Tujuan dari teknik ini adalah untuk mendekati daerah pertahanan lawan dan dalam usaha untuk mencari kesempatan untuk mencetak angka. Selain itu, dribble juga dilakukan untuk menghindari lawan dan tekanan yang dilakukan oleh lawan.

Berdasarkan hasil observasi pada kegiatan latihan rutin kelompok SMA di Hurricane Basketball Club. Kemampuan untuk melakukan dribble terutama pada 
Pengaruh Metode Latihan Figure Eight With Dribbling dan Metode Latihan Neck Waist And Leg Circles Terhadap Hasil Dribble pada Hurricane Basketball Club di Kecamatan Gemolong

Seno Widyantoro, Agustanico Dwi Muryadi, Karlina Dwijayanti

peserta pemula belum maksimal. Bola yang digiring masih sering mengarah keluar jangkauan tangan sehingga sulit dikendalikan, karena pada saat melakukan dribble pergelangan tangan belum terbiasa mengolah bola atau memainkan bola dengan baik. Posisi telapak tangan tidak berbentuk mangkuk pada saat menggiring. Bola dipantulkan dari tangan ke lantai dengan menggunakan pantulan telapak tangan bukan oleh kekuatan jari sehingga arah bola melebar dan telapak tangan menjadi sakit.

Keadaan ini sangat wajar mengingat para pemain adalah pebasket pemula yang belum memahami bagaimana dribble bola dengan posisi telapak tangan yang tepat. Kondisi tersebut harus diperbaiki agar terjadi peningkatan kemampuan dribble menjadi lebih baik, sehingga kualitas bermain Hurricane Basketball Club khusus kelompok SMA menjadi lebih baik.

Di lapangan kondisinya sangat kompleks dan dinamis. Dribble dominan dilakukan oleh tangan kanan karena lebih bertenaga dan bola lebih terkontrol. Pengontrolan bola hanya dapat dilakukan dengan tata cara dribble bola dengan menggunakan kelenturan jari dengan posisi telapak tangan dan jari membentuk mangkuk. Pebasket yang tidak mampu mengendalikan dribble mudah terkecoh dengan gerakan lawan. Lawan dapat merebut dan memperkirakan arah bola.

Berdasarkan kondisi yang nyata di lapangan bahwa kemampuan teknik dasar adalah faktor penting yang turut menentukan keberhasilan tim dalam permainan bola basket. Kemampuan teknik dribble hanya dapat diperoleh dengan latihan. Latihan yang diperlukan adalah latihan yang efektif dan dibantu dengan metode latihan Figure Eight With Dribbling dan metode latihan Neck, Waist And Leg Circles yang tepat untuk melatih kemampuan dribble.

Menurut Sucipto (2010:108) Metode latihan Figure Eight With Dribbling merupakan tahap pengembangan dari latihan ball handling. Yang hanya memindahmindahkan bola dari tangan kanan ke tangan kiri dan sebaliknya tanpa adanya kontak lain selain bola degan tangan. Pada metode latihan ini peserta mulai belajar 
Pengaruh Metode Latihan Figure Eight With Dribbling dan Metode Latihan Neck Waist And Leg Circles Terhadap Hasil Dribble pada Hurricane Basketball Club di Kecamatan Gemolong

Seno Widyantoro, Agustanico Dwi Muryadi, Karlina Dwijayanti

drible bola dengan pola lingkaran membentuk angka delapan melewati ruang antara kaki kanan dengan kaki kiri. Latihan ini bertujuan melatih kemampuan koordinasi peserta dan juga ketrampilan gerak dasar bermain bola basket

Menurut Sucipto (2010:110) Neck, Waist And Leg Circles merupakan salah satu bentuk latihan penguasaan bola dan dribbling dengan cara memindahkan bola dari tangan kanan ke tangan kiri dalam gerakan melingkar di sekitar leher, pinggang dan lutut saat anda berdiri dengan kaki selebar bahu. Kemudian melakukan ini dengan memutarkan bola pada leher, pinggang dan kedua lutut yang dirapatkan. Pada tahap ini peserta dilatih agar dapat menguasai bola dalam keadaan rendah atau dibawah pinggang.

Berdasarkan latar belakang yang dikemukakan maka penelitian ini akan mengambil judul : Pengaruh Metode Latihan Figure Eight With Dribbling Dan Metode Latihan Neck, Waist And Leg Circles Hasil Dribble Pada Pemain Hurricane Basketball Club di Kecamatan Gemolong.

\section{Metode}

Penelitian yang penulis buat merupakan jenis penelitian eksperimen. Menurut Ali Maksum (2012:6) menyatakan bahwa "Penelitian eksperimen adalah penelitian yang dilakukan secara ketat untuk mengetahui hubungan sebab akibat diantara variabel. Salah satu ciri utama penelitian eksperimen adalah adanya perlakuan (treatment) yang dikarenakan yang dikenakan kepada subjek atau objek". Karena penelitian ini merupakan penelitian eksperimen maka akan diberikan perlakuan (treatment) pada sampel yang penulis ambil. Dalam penelitian ini penulis menggunakan metode penelitian pretest post-test design. Sampel akan dibagi menjadi dua kelompok penelitian dengan menggunakan metode ordinal. Eko Putro Widoyoko (2013:24) menyatakan “ordinal merupakan data yang mempunyai jenjang, sehingga responden dapat diurutkan jenjangnya sesuai dengan karakteristik yang ada pada dirinya". Dalam penelitian ini penulis akan membagi data ordinal bedasarkan hasil pretest. 
Pengaruh Metode Latihan Figure Eight With Dribbling dan Metode Latihan Neck Waist And Leg Circles Terhadap Hasil Dribble pada Hurricane Basketball Club di Kecamatan Gemolong

Seno Widyantoro, Agustanico Dwi Muryadi, Karlina Dwijayanti

Populasi yang penulis ambil adalah pemain Hurricane Basketball Club putra dan putri yang berjumlah 85 orang. Sedangkan dalam penelitian ini sampel yang digunakan pemain putra kelompok SMA adalah 30 orang. Penelitian ini dilakukan selama 6 minggu dengan 3 kali pertemuan dalam seminggu.

Pengumpulan data pada penelitian ini dengan menggunakan tes dribble zigzag dalam permainan bola basket untuk mengukur penguasaan gerak menggiring bola menurut Nurhasan (2013:240) dengan rute tes penguasaan Gerak Menggiring Bola (Dribbling) yang digunakan untuk pengambilan data.

A. Petunjuk penilaian

Tabel 1. Penilaian Penguasaan Gerak Menggiring Bola (Dribbling)

\begin{tabular}{|c|c|c|c|c|c|c|}
\hline \multirow{2}{*}{ Tahapan Gerakan } & \multirow{2}{*}{ No } & \multirow{2}{*}{ Kriteria Penilaian } & \multicolumn{4}{|c|}{ Skor } \\
\hline & & & 1 & 2 & 3 & 4 \\
\hline \multirow{5}{*}{$\begin{array}{l}\text { I. } \\
\text { Persiapan }\end{array}$} & 1 & Berdiri seperti melakukan stance & & & & \\
\hline & 2 & Salah satu kaki berada didepan & & & & \\
\hline & 3 & $\begin{array}{l}\text { Sikap lengan kanan tegak lurus } \\
\text { dengan lengan bawah sejajar } \\
\text { dengan tanah atau lantai }\end{array}$ & & & & \\
\hline & 4 & $\begin{array}{l}\text { Pandangan pada waktu pertama } \\
\text { kali belajar kearah bola }\end{array}$ & & & & \\
\hline & 5 & $\begin{array}{l}\text { Makin lama pandangan diubah } \\
\text { melihat bola akan tetapi kedepan } \\
\text { kurang lebih } 3 \text { meter }\end{array}$ & & & & \\
\hline \multirow{4}{*}{$\begin{array}{c}\text { II. } \\
\text { Pelaksanaan }\end{array}$} & 6 & $\begin{array}{l}\text { Untuk dribble bola lebih kedepan } \\
\text { serta kejarlah bola tersebut }\end{array}$ & & & & \\
\hline & 7 & $\begin{array}{l}\text { Saat melakukan dribble nadam } \\
\text { direndahkan }\end{array}$ & & & & \\
\hline & 8 & $\begin{array}{l}\text { Lindungi bola basket dengan } \\
\text { lengan kiri serta kaki kiri didepan }\end{array}$ & & & & \\
\hline & 9 & $\begin{array}{l}\text { Lengan kanan bergerak dan } \\
\text { mengikuti pantulan bola }\end{array}$ & & & & \\
\hline \multirow{3}{*}{$\begin{array}{l}\text { III. } \\
\text { Gerak lanjut }\end{array}$} & 10 & $\begin{array}{l}\text { Memperhatikan bola kearah } \\
\text { pantulan }\end{array}$ & & & & \\
\hline & 11 & Bola bergerak kearah pantulan & & & & \\
\hline & 12 & Gerakan lengan kearah bola & & & & \\
\hline & & mlah nilai & & & & \\
\hline
\end{tabular}

Tabel

2. Kriteria Norma Penilaian Menggiring Bola (Dribbling) Bola Basket 


\begin{tabular}{ccc} 
Persentase & Rentan Skor & Nilai Produk Menggiring \\
\hline $80-100 \%$ & $38-48$ & Baik sekali \\
$66-79 \%$ & $32-37$ & Baik \\
$56-65 \%$ & $27-31$ & Cukup \\
$41-55 \%$ & $20-26$ & Kurang \\
$0-40 \%$ & $0-19$ & Kurang sekali \\
\hline
\end{tabular}

Sumber : Nurhasan (2013:205)

\section{Hasil dan Pembahasan}

Data hasil penelitian sebagai berikut :

Tabel 3. Hasil Tes Awal ( Pre Test)

\begin{tabular}{lllll} 
Kelompok & Max & Min & SD & Mean \\
\hline $\begin{array}{l}\text { Figure Eight With } \\
\text { Dribbling }\end{array}$ & 29 & 19 & 2.815 & 22.93 \\
$\begin{array}{l}\text { Neck Waist And } \\
\text { Leg Circle }\end{array}$ & 27 & 19 & 2.610 & 22.67 \\
\hline
\end{tabular}

Berdasarkan hasil tes awal menunjukkan rata-rata tingkat kemampuan dribble kelompok Figure Eight With Dribbling sebesar 22,93, dengan nilai tertinggi sebesar 29, nilai terendah 19, dan standar deviasi sebesar 2,815. Sedangkan rata-rata untuk kelompok Neck Waist And Leg Circles sebesar 22,67, dengan nilai tertinggi 27, nilai terendah 19 dan standar deviasi sebesar 2,610. Dilihat dari nilai rata-rata tersebut menunjukkan kedua kelompok mempunyai tingkat kemampuan dribble yang sama.

Tabel 4. Hasil Tes Akhir ( Post-test)

\begin{tabular}{lllll} 
Kelompok & Max & Min & SD & Mean \\
\hline $\begin{array}{l}\text { Figure Eight With } \\
\text { Dribbling }\end{array}$ & 41 & 34 & 2.086 & 37.07 \\
$\begin{array}{l}\text { Neck Waist And } \\
\text { Leg Circle }\end{array}$ & 35 & 29 & 1.699 & 32.20 \\
\hline
\end{tabular}


Pengaruh Metode Latihan Figure Eight With Dribbling dan Metode Latihan Neck Waist And Leg Circles Terhadap Hasil Dribble pada Hurricane Basketball Club di Kecamatan Gemolong

Seno Widyantoro, Agustanico Dwi Muryadi, Karlina Dwijayanti

Berdasarkan hasil tes akhir menunjukkan rata-rata kemampuan dribble kelompok Figure Eight With Dribbling sebesar 37,07, nilai tertinggi 41, nilai terendah 34 dan standar deviasi sebesar 2,086. Sedangkan rata-rata tingkat kemampuan dribble kelompok Neck Waist And Leg Circles sebesar 32,20, nilai tertinggi 35, nilai terendah 29, dan standar deviasi sebesar 1,699. Dilihat dari nilai rata-rata tersebut menunjukkan kelompok Figure Eight With Dribbling lebih tinggi tingkat kemampuan dribble dari kelompok Neck Waist And Leg Circles, hal ini menunjukkan bahwa Figure Eight With Dribbling lebih efektif meningkatkan hasil dribble pada pemain Hurricane Basketball Club.

\section{PEMBAHASAN}

1. Terdapat Pengaruh Metode Latihan Figure Eight With Dribbling Terhadap Hasil Dribble pada Pemain Hurricane Basketball Club.

Berdasarkan hasil persentase peningkatan dapat dilihat adanya pengaruh metode latihan Figure Eight With Dribbling terhadap hasil dribble pada pemain Hurricane Basketball Club dengan diperoleh nilai 61,66\% untuk metode latihan Figure Eight With Dribbling dan diperoleh nilai rata-rata pada kelompok Figure Eight With Dribbling sebesar 22,93 (pretest) dan 37,07 (post-test), Berdasarkan data tersebut dapat disimpulkan bahwa terdapat pengaruh dalam metode latihan Figure Eight With Dribbling.

Faktor utama yang mempengaruhi meningkatnya hasil dribble dengan metode latihan Figure Eight With Dribbling pada pemain Hurricane Basketball Club yaitu latihan dribble yang diterapkan merupakan latihan fundamental atau dasar latihan dasar ball handling dalam meningkatkan kemampuan pemain dalam melakukan dribble. Dengan pola latihan Figure Eight With Dribbling dirancang untuk melatih sentuhan pada bola, memperkuat tangan pemain untuk mengontrol, keluwesan gerak tangan saat menggiring bola sehingga hasil yang 
Pengaruh Metode Latihan Figure Eight With Dribbling dan Metode Latihan Neck Waist And Leg Circles Terhadap Hasil Dribble pada Hurricane Basketball Club di Kecamatan Gemolong

Seno Widyantoro, Agustanico Dwi Muryadi, Karlina Dwijayanti

diperoleh menunjukan adanya pengaruh latihan Figure Eight With Dribbling terhadap hasil dribble.

2. Terdapat Pengaruh Metode Latihan Neck, Waist And Leg Circles Terhadap Hasil Dribble pada Pemain Hurricane Basketball Club.

Berdasarkan hasil persentase peningkatan dapat dilihat adanya pengaruh metode latihan Neck, Waist And Leg Circles terhadap hasil dribble pada pemain Hurricane Basketball Club tahun 2020 dengan diperoleh nilai 42,03\%untuk metode latihan Neck, Waist And Leg Circles dan diperoleh nilai rata-rata pada kelompok Neck, Waist And Leg Circles sebesar 22,67 (pretest) dan 32,20 (post-test), Berdasarkan data tersebut dapat disimpulkan bahwa terdapat pengaruh dalam metode latihan Neck, Waist And Leg Circles.

Faktor utama yang mempengaruhi meningkatnya hasil dribble dengan metode latihan Neck, Waist And Leg Circles pada pemain Hurricane Basketball Club yaitu salah satu bentuk latihan penguasaan bola dan dribbling dengan cara memindahkan bola dari tangan kanan ke tangan kiri dalam gerakan melingkar di sekitar leher, pinggang dan lutut saat anda berdiri dengan kaki selebar bahu. Pada tahap ini peserta dilatih agar dapat menguasai bola dengan menitik beratkan pola latihan untuk keluwesan tangan saat menggiring bola. Sehingga kemampuan dribble peserta disaat keluwesan tangan meningkat dengan latihan fundamental akan didapatkan hasil yang lebih baik.

Menurut Sucipto (2010:27) Setiap cabang olahraga mempunyai ciri khas masing-masing salah satunya teknik dan taktik. Setiap teknik dasar yang ada merupakan gerakan yang fundamental yang harus dimiliki dan dikuasai oleh setiap pemain. Begitu juga dalam olahraga permainan bola basket sangat banyak variasi untuk memasukan bola ke dalam keranjang yang gerakannya berasal dari teknik dasar yang dikembangkan dan dilatih secara berkelanjutan dan sistematis. Latihan adalah proses yang sistematis dari berlatih atau bekerja yang 
Pengaruh Metode Latihan Figure Eight With Dribbling dan Metode Latihan Neck Waist And Leg Circles Terhadap Hasil Dribble pada Hurricane Basketball Club di Kecamatan Gemolong

Seno Widyantoro, Agustanico Dwi Muryadi, Karlina Dwijayanti

dilakukan secara berulang-ulang dengan kian hari kian menambah jumlah beban latihan atau pekerjaannya dimulai dari latihan fundamental atau dasar.

3. Terdapat Perbedaan Pengaruh Latihan Metode Latihan Figure Eight With Dribbling dan Metode Latihan Neck, Waist And Leg Circles Terhadap Hasil Dribble pada Pemain Hurricane Basketball Club.

Berdasarkan hasil pengujian perbedaan yang dilakukan pada tes akhir antara kelompok 1 dan kelompok 2 berdasarkan hasil pengujian perbedaan tes akhir dengan T-Test (Independent samples t test) antara kelompok 1 (Figure Eight With Dribbling) dan kelompok 2 (Neck, Waist And Leg Circles) diperoleh nilai signifikan sebesar 0,000 < 0,05, yang berarti ada perbedaan pengaruh metode latihan Figure Eight With Dribbling dan metode latihan Neck, Waist And Leg Circles terhadap hasil dribble pada pemain Hurricane Basketball Club tahun 2020. Perbedaan hasil tersebut karena adanya perbedaan karakteristik dan gerakan antara metode latihan Figure Eight With Dribbling dan metode latihan Neck, Waist And Leg Circles terhadap hasil dribble.

Tes dribble zig-zag ini bertujuan untuk mengukur tingkat kemampuan siswa dalam melakukan tehnik dasar dribble pada olahraga bola basket di Hurricane Basketball Club. Figure Eight With Dribbling dan metode latihan Neck, Waist And Leg Circles merupakan metode latihan ball handling yang memiliki tujuan untuk meningkatkan kemampuan dribble pemain. Hanya saja perbedaan adalah metode latihan Figure Eight With Dribblng yang lebih menitik beratkan keluwesan peserta didik dalam mengolah bola, memainkan bola, dan penguasaan bola yang lebih dinamis yaitu menggiring bola membentuk angka delapan di sekitar kaki, sedangkan Neck, Waist And Leg Circles yang lebih statis hanya memutarkan bola mengelilingi leher, pinggang dan kaki saja. Dengan demikian diduga metode latihan Figure Eight With Dribbling dan metode latihan Neck, Waist And Leg Circles memiliki perbedaan terhadap ketrampilan melakukan dribble. 
Pengaruh Metode Latihan Figure Eight With Dribbling dan Metode Latihan Neck Waist And Leg Circles Terhadap Hasil Dribble pada Hurricane Basketball Club di Kecamatan Gemolong

Seno Widyantoro, Agustanico Dwi Muryadi, Karlina Dwijayanti

Hasil tersebut menunjukkan bahwa Figure Eight With Dribbling lebih mampu memberikan sumbangan yang positif dalam meningkatkan kemampuan dribble dibandingkan dengan Neck, Waist And Leg Circles. Perlakuan ini merupakan salah satu treatment untuk meningkatkan ketrampilan melakukan dribble yang dimiliki untuk lebih baik dari sebelum treatment.

Latihan keterampilan dribble dengan menggunakan metode latihan Figure Eight With Dribbling merupakan tahap pengembangan dari latihan ball handling. Dengan konsep yang ball handling yang hanya memainkan bola memindahmindahkan bola dari tangan kanan ke tangan kiri dan sebaliknya tanpa adanya kontak lain selain bola dengan tangan. Pada metode latihan ini peserta mulai belajar dribble bola dengan pola lingkaran membentuk angka delapan melewati ruang antara kaki kanan dengan kaki kiri. Latihan ini bertujuan untuk melatih kemampuan koordinasi siswa dan juga melatih ketrampilan dalam melakukan gerak dasar dribble siswa bermain basket.

Dari uraian di atas bisa dilihat antara metode latihan Figure Eight With Dribbling dan metode latihan Neck, Waist And Leg Circles terdapat pengaruh yang berbeda pada peningkatan hasil dribble pada pemain Hurricane Basketball Club, Dan disimpulkan bahwa metode latihan Figure Eight With Dribbling lebih baik pengaruhnya dibandingkan metode latihan Neck, Waist And Leg Circles.

\section{Simpulan}

Berdasarkan hasil penelitian dan analisis data yang telah dilakukan, dapat diambil kesimpulan sebagai berikut :

1. Terdapat pangaruh latihan metode latihan Figure Eight With Dribbling terhadap hasil dribble pada pemain Hurricane Basketball Club tahun 2020 dengan nilai ratarata pretest sebesar 22,93 dan nilai rata-rata post-test sebesar 37,07 dengan pola latihan yang menitik beratkan kelentukan, sentuhan tangan pada bola, 
Pengaruh Metode Latihan Figure Eight With Dribbling dan Metode Latihan Neck Waist And Leg Circles Terhadap Hasil Dribble pada Hurricane Basketball Club di Kecamatan Gemolong

Seno Widyantoro, Agustanico Dwi Muryadi, Karlina Dwijayanti

memperkuat kontrol tangan saat mengiring bola, menggiring bola memutari kaki membentuk angka 8 sehinga didapatkan pengaruh terhadap hasil dribble.

2. Terdapat pangaruh latihan metode latihan Neck, Waist And Leg Circles terhadap hasil dribble pada pemain Hurricane Basketball Club tahun 2020 dengan nilai rata-rata pretest sebesar 22,67 dan nilai rata-rata post-test sebesar 32,20 karena latihan yang diberikan dari dasar ball handling dengan melatih keluwesan tangan mengola bola, memindahkan bola dari tangan kanan ke kiri ataupun sebaliknya dengan memutari leher, pinggang dan kaki sehinggan didapatkan pengaruh terhadap hasil dribble.

3. Pada treatment Figure Eight With Dribbling lebih baik dibandingkan treatment Neck, Waist And Leg Circles terhadap terhadap hasil dribble pada pemain Hurricane Basketball Club.

\section{Refrensi}

Sucipto. 2010. Permainan Bola Basket. Bandung : UPT - UPI.

Nurhasan. 2013. Tes dan Pengukuran. Bandung : FPOK.

Maksum, A. 2012. Metodologi Penelitian dalam Olahraga. Surabaya : UNESA.

Widoyoko, E. 2013. Teknik Penyusunan Instrumen Penelitian. Yogyakarta : Pustaka Pelajar.

Sugiyono. 2012. Statistika untuk Penelitian. Bandung: Alfabeta.

Sugiyono. 2016. Metode Penelitian Kuantitatif Kualitatif, dan RED. Bandung : Alfabeta.

Sunarno, A. 2011. Metode Penelitian Keolahragaan. Surakarta : Yuma Pustaka.

Upton, P. 2012. Psikologi Perkembangan. Bandung : Erlangga.

Wiarto, G. 2013. Fisiologi dan Olahraga. Yogyakarta : Graha Ilmu. 